\title{
DECONTAMINATION OF BACTERIA FROM WATER WITH MODERATE ELECTRIC AND MAGNETIC FIELDS
}

\author{
Alakaparampil J. Varkey, Mgidi D. Dlamini, and Simiso K. Mkhonta* \\ Department of Physics, University of Swaziland, Private Bag 4, Kwaluseni, M201, Swaziland
}

\begin{abstract}
Bacteria play a key role in both human health and disease. One of the most prevalent harmful bacteria is $E$. coli which is responsible for several illnesses ranging from diarrhea, stomach cramp and fever. In this work we explore the application of moderate electric or magnetic fields for treating deionized water that is contaminated with $E$. coli. We found that moderate alternating electric (AC) fields (10 $\mathrm{V} / \mathrm{cm}$ to $1 \mathrm{kV} / \mathrm{cm}$ ) and moderate static magnetic fields $(10$ to $65 \mathrm{mT}$ ) can significantly inactivate $E$. coli by up to $90 \%$ or more. This provides the possibilities of developing a low cost and a practical bacteria inactivation technique using electric or magnetic fields.
\end{abstract}

Keywords: bacterial inactivation; drinking water; electromagnetic fields; electroporation; Escherichia coli

\section{INTRODUCTION}

Microbial contamination of food and water is globally considered to be a major health hazard [1]. One of the most deadly microbes is the Escherichia coli (E.coli) bacteria (strain 0157:H7) which can have an infective dose even as low as 10 colony forming units (CFU) and is mostly transmitted through food and water [2]. There are several techniques used for inactivating bacteria and other microbes from water and other liquid supplies. These include chemical processes such as chlorine disinfection, physical processes such as filtration, UV light treatment, thermal treatment, and the application of electric and magnetic fields. There is growing interest in the area of food science on the use of electric and magnetic fields in the decontamination or preservation of liquid food [3-6]. There is also a similar interest in the field of medicine to use electric and/or magnetic E/M fields to increase the efficacy of antibiotics against pathogens $[7,8]$.

Previous studies have shown that there are three main factors that affect microbial inactivation by electric and/or magnetic fields: (i) medium type $(\mathrm{pH}$, ionic strength, conductivity, and ambient temperature), (ii)

*To whom all correspondence should be addressed Email: smkhonta@uniswa.sz, Tel: (268) 251 70247, University of Swaziland, P/Bag 4, Kwaluseni, M200 microbial entity (microbe type, growth stage, and microbe concentration), and (iii) form of the applied electromagnetic field (field intensity, frequency of $A C$ field, and exposure time). For electric fields, another contributing factor is the type of electrodes, whether the electrodes are insulated or not. Low intensity electric fields (less than $10 \mathrm{~V} / \mathrm{cm}$ ) or low magnetic fields (less than $1 \mathrm{mT}$ ) inhibit microbial growth through electro-phoresis or magneto-phoresis whereby the cellular ions or charged organelles are forced to flow and align in certain directions. Low E/M electric fields influence the electrical activity in living cells and affect cell division processes [9]. Moderate electric fields $(10 \mathrm{~V} / \mathrm{cm}$ to $1 \mathrm{kV} / \mathrm{cm})$ or moderate magnetic fields (1mT to $1 \mathrm{~T}$ ) have been found to increase the permeability of a cell membrane [7, 10-14]. The increased permeabilization affects ion transport into the cells and thus can lead to the loss of microbe viability. If the increased permeabilization is driven by electric (magnetic) fields the process is called electroporation (magnetoporation), respectively. Electroporation or magnetoporation becomes irreversible at high electric fields ( $>$ tens of $\mathrm{kV} / \mathrm{cm})$ or high magnetic fields $(>1 \mathrm{~T})$. This 
process explains significant inactivation of bacteria in high electromagnetic fields. For example, Johnstone and Bodger [15] found the DC electric field (about $30 \mathrm{kV} / \mathrm{cm}$ ) completely inactivated. $E$ coli inoculated in deionized water within an exposure time of less $17 \mathrm{~ms}$. AC electric fields at the same intensity reduced the bacteria count by three orders of magnitude from an initial viable bacteria concentration of $10^{5}-10^{6}$ cells per $\mathrm{cm}^{3}$.

This work investigates the effects and limits of moderate AC electric fields and static magnetic fields on the survival of $E$. coli bacteria in deionized water. Our objective is to develop a low cost and practical technique for drinking water disinfection. Previous studies on the use of moderate intensity electric fields were performed with the $E$. coli bacteria in liquid foods [3] and also with focus on the effects of frequency of AC fields [9]. The inhibitory effects of static magnetic fields were found in $E$. coli bacteria in a urine sample [16]. In this study the E. coli bacteria is inoculated in deionized water.

\section{MATERIALAS AND METHODS}

To obtain a fixed concentration of $E$. coli, $0.15 \mathrm{~g}$ of $E$. coli (concentrate) was dissolved in $250 \mathrm{~mL}$ of distilled and deionized water. $100 \mathrm{~mL}$ of this solution was poured in a beaker and two carbon electrodes were placed inside it on opposite sides (Fig.1). The temperature of the sample was maintained at $23 \pm 1{ }^{\circ} \mathrm{C}$. To study the deactivation/growth rate of the $E$. coli in the presence of applied electric and/or magnetic fields, the following procedure was carried out.

\subsection{Alternating (AC) electric field}

The electrodes were connected to a static voltage source as shown in Figure 1. The AC voltage at a frequency of $50 \mathrm{~Hz}$ was increased from $5.0 \mathrm{~V}$ to $50.0 \mathrm{~V}$ in steps of 5.0 V. For each voltage applied, the $E$. coli was

*To whom all correspondence should be addressed Email: smkhonta@uniswa.sz, Tel: (268) 251 70247, University of Swaziland, P/Bag 4, Kwaluseni, M200 exposed to the electric field for a period of one hour and the E. coli colony count was measured. Thereafter the time interval was increased in steps of one hour up to a maximum period of eight hours and the colony count was done for each voltage.

\subsection{Static magnetic field}

This is similar to the electric field but the count rate was against magnetic field strength. The data obtained were: (a) colony count versus magnetic field strength for a fixed time interval ( $2 \mathrm{~h}$ ) and (b) colony count versus time of exposure for a fixed magnetic field strength $(65 \mathrm{mT})$

This is similar to the electric field but the count rate was against magnetic field strength. The data obtained were: (a) colony count versus magnetic field strength for a fixed time interval ( $2 \mathrm{~h}$ ) and (b) colony count versus time of exposure for a fixed magnetic field strength $(65 \mathrm{mT})$

\section{RESULTS AND DISCUSSIONS}

Variation of $E$. coli count with applied AC electric field for 2 hours is shown in Fig. 2. For AC electric fields with strength between $11 \mathrm{~V} / \mathrm{cm}$ to $1.1 \mathrm{kV} / \mathrm{cm}$, the bacteria inactivation of $25 \%$ to $100 \%$ observed. An extremely high decrease in bacteria count was obtained at the lower electric field intensity of $11 \mathrm{~V} / \mathrm{cm}$, though these results also depend on the exposure time. For example, at the electric field intensity of 1 $\mathrm{kV} / \mathrm{cm}$, the decrease in the bacteria count was at least $50 \%$ or more for exposure time of above six and half hours as shown in Fig. 2. The effectiveness of electric field of lower intensities in our study can be attributed to the electro-thermal effect that is dependent of the conductivity of the medium. Higher electric field intensities can lead to Joule heating effect [10] that can affect the bacteria deactivation mechanism. 
Variation of E.coli count in a sample exposed to various static magnetic fields for two hours is shown in Fig. 3. Again, our results show that magnetic fields between $10 \mathrm{mT}$ to $65 \mathrm{mT}$ have an inhibitory effect on $E$. coli. The maximum reduction in bacteria count occurred at $65 \mathrm{mT}$ with the count declining by $77 \%$. We found that for exposure time greater than one hour, the bacteria count declined by between $40 \%$ and $90 \%$ at $65 \mathrm{mT}$ as shown in Fig. 3. Our results indicate an insignificant decline in the bacteria count for magnetic fields at $20 \mathrm{mT}$ and $30 \mathrm{mT}$. However, in a recent study, MousavianRoshanzamir et al [16] found that static magnetic field $(20 \mathrm{mT})$ produced a significant decline in survival rate of $E$. coli bacteria in urine samples. This conflicting evidence might be as result of the different medium types.

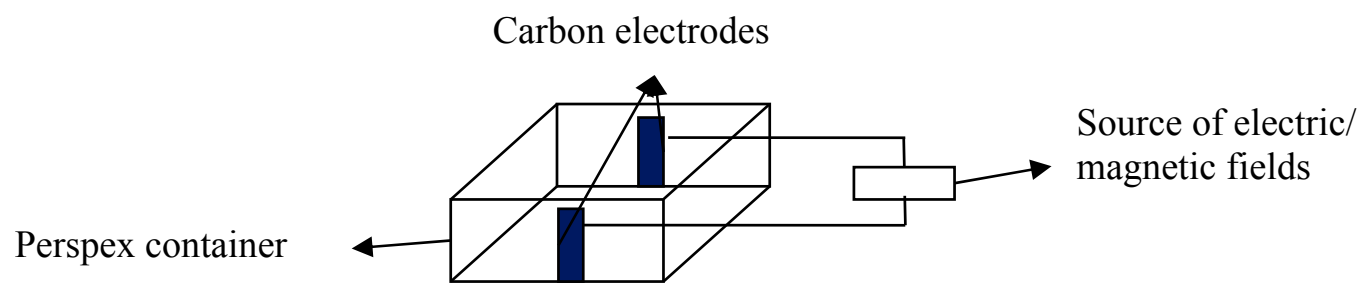

Fig. 1. Schematic diagram of the experimental setup.

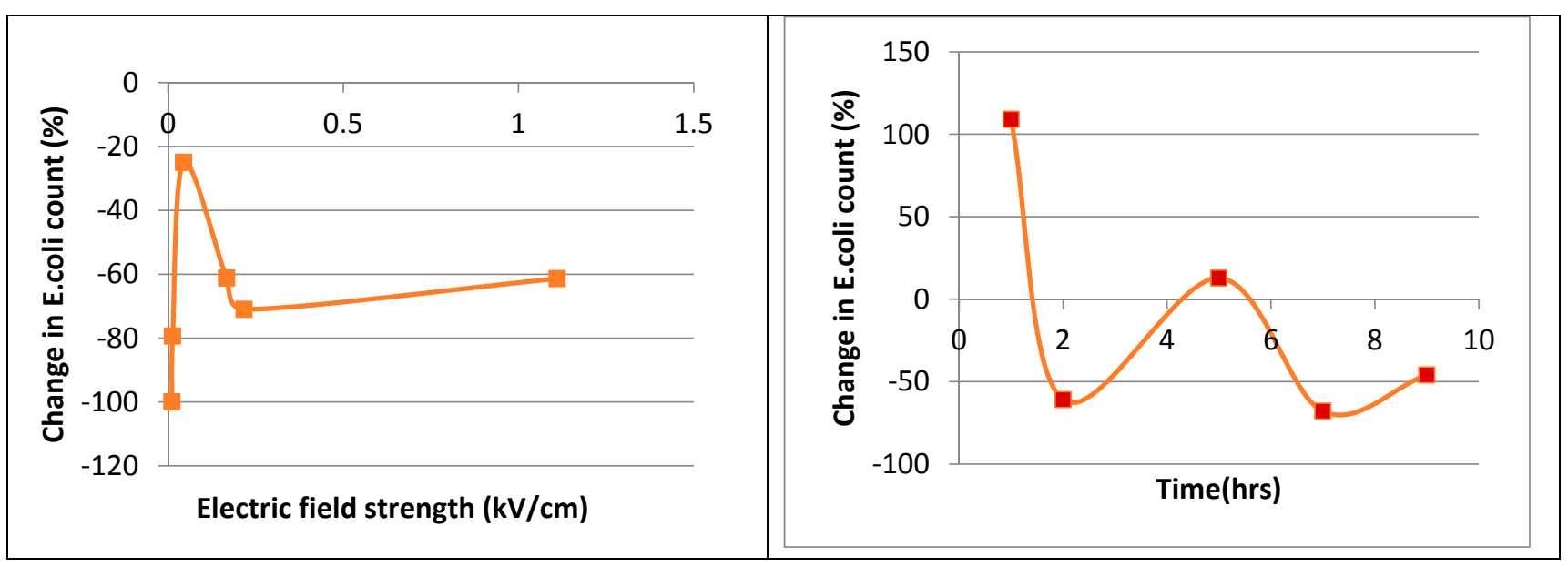

Figure 2: The change in E. coli bacteria count (Vs.) exposed AC electric field for 2 hours (left panel). Changes in $E$. coli bacteria count in a sample exposed in AC electric field (1 $\mathrm{kV} / \mathrm{cm}$ ) for different exposure periods (right panel). 


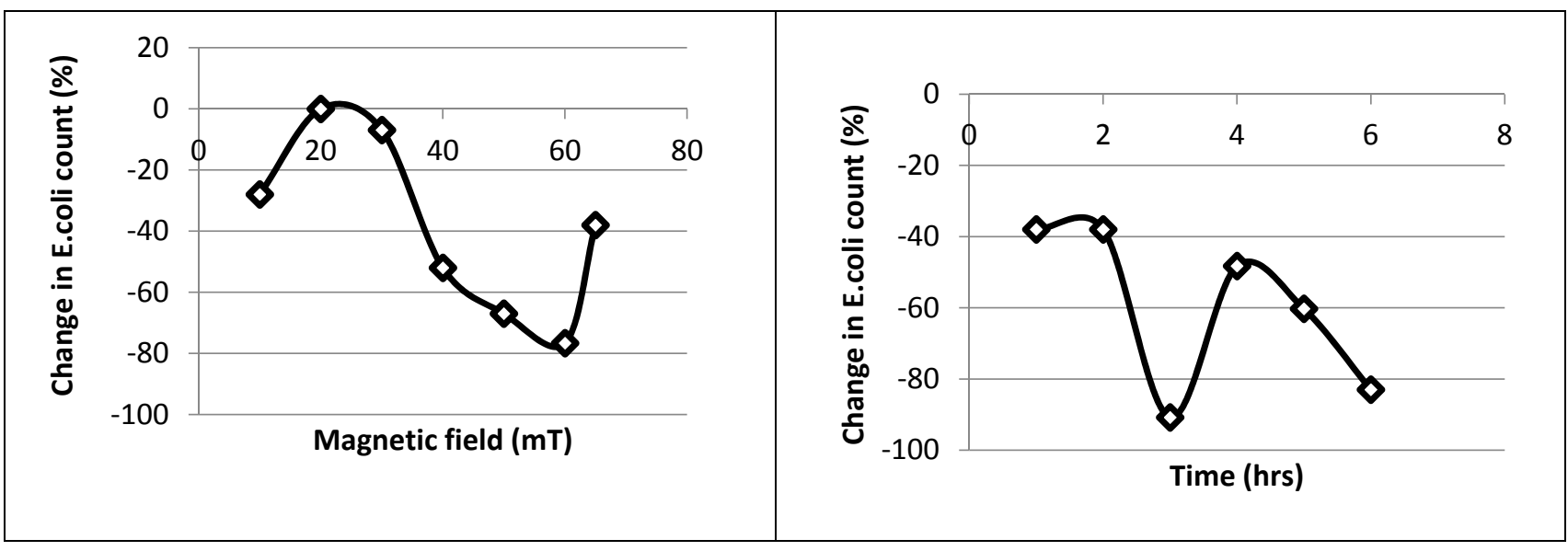

Figure 3: The change in E. coli bacteria count exposed to static magnetic fields for 2 hours (left panel). Changes in $E$. coli bacteria count in a sample exposed to a static magnetic field (65 mT) for different exposure periods (right panel).

\section{CONCLUSIONS}

In summary, the results obtained in this study show that exposing $E$. coli inoculated in deionized water to moderate AC electric or moderate magnetic fields leads to the decline bacteria count. While previous studies have shown that high intensity electric field may be more effective as a disinfectant of contaminated liquid, moderate fields are more practical for developing domestic disinfection devices.

It is suggested that more elaborate studies both on the experimental and theoretical aspects of the subject are needed, placing emphasis on the importance of an ion-free environment for the microorganisms.

\section{ACKNOWLEDGEMENTS}

The researchers acknowledge, with appreciation Mr. S. B. Mavuso and Mr. M. Dlamini for their tireless input under work pressure during the execution of the project. Funding for the project was generously provided by the UNISWA Research Board.

\section{REFERENCES}

Barbosa-Canovas, G.V., Gondora-Neito, M.M. , Pothakamury, U.R. and Swanson, B.G. (1999). Preservation of foods with pulsed electric fields. Academic Press, Washington, D.C.

Barbosa-Canovas, G.V. and Zhang, Q.H. (2001). Pulsed electric fields in food processing: fundamental aspects and applications. Technomic Publishing Co., Washington, D.C.

Filipic, J., Kraigher, B., Tepus, B., Kokol, V., and Mandic-Mulec, I., (2012). Effects of lowdensity magnetic fields on the growth and activities of wastewater bacteria Escherichia coli and Pseudomonas putida. J. Bioresource Technology 120 (4) 225-232.

Fojt, L., Strasak, L., Vetterl, V., and Smarda, J. (2004). Comparison of the low-frequency magnetic field effects on bacteria Escherichia coli, Leclercia adecarboxylata and Staphylococcus aureus. Bioelectrochemistry 63 337-341. 
Gaynor, P.T., and Bodger, P.S. (1995). Ballon model of biological cell electropermeabilisation in relation to the radius dependence of membrane dielectric breakdown. IEE Proc. Sci. Meas. Technol. 142 (4) 277-282.

Giladi, M., Porat, Y., Blatt, A., Wasserman, Y., and Kirson, E.D. (2008). Microbial growth inhibition by alternating electric fields. Antimicrobial Agent and Chemotherapy $\mathbf{5 2}$ (10) 3517-3522.

Greig, J.D., Todd, E.C.D., Bartleson, C., and Michaels, B. (2010). Infective Doses and Pathogen Carriage. Presentation at the Food Safety Education Conference, Atlanta, USA. URL:

https://www.fsis.usda.gov/PDF/Atlanta2010/S lides FSEC JGreig Doses.pdf (Accessed 4 July 2017)

Johnstone, P.T. and Bodger, P.S. (1997). High voltage disinfection of liquids. IPENZ Transactions 24(1) 38 30-35.

Kermanshahi, R.K. and Sailani, M.R. (2005). Effect of static electric field treatment on multiple antibiotic-resistant pathogenic strains of Escherichia coli and Staphylococcus aureus. Journal of Microbiology Immunology and Infection 38 394-398.

Mousavian-Roshanzamir, S. and Makhdoumi-Kakhki, A. (2017). The inhibitory effects of static magnetic fields on Escherichia coli from two different source at short exposure time. Reports of Biochemistry and Molecular Biology 5 (2) 112-116.

Oziemblowski, M. and Kopec, W. (2005). Pulsed electric as an unconditional method of food preservation. Pol. J. Food Nutr. Sci. 15 31-35.

\footnotetext{
*To whom all correspondence should be addressed Email: smkhonta@uniswa.sz, Tel: (268) 25170247, University of Swaziland, P/Bag 4, Kwaluseni, M200
}

Puc, M., Corovic, S., Flisar, K., Petkovsek, M., Nastran, J., and Miklavcici, D. (2004). Techniques of signal generation required for electropermeabilization: Survey of electropermeabilization devices. Bioelectrochemistry 65 113-124.

Shawki, M.M. and Gaballah A. (2015). The effect of low AC electric field on bacteria cell death. Romanian J. Biophys. 25 (2) 163-172.

Trainito, C. (2015). Study of cell membrane permeabilization induced by pulsed electric field - electric field - electrical modeling and characterization on biochip. PhD Thesis, Universite Paris-Saclay.

Vega-Mercado, H., Martin-Belloso, O., Quin B.L., Cahng, F.J., Gondora-Neito, M.M., Barbosa-Canovas, G.V. and Swanson, B.G. (1997). Non-thermal food preservation: pulsed electric fields. Trends Food Sci. Tech. 8 151-157.

World Health Organization (2015). WHO estimates of the global burden of foodborne diseases.

URL:http://www.who.int/foodsafety/publicatio ns/foodborne disease/fergreport/en/ (Accessed 5 June 2017). 